\title{
Perceived Corruption and Individuals' Life Satisfaction: The Mediating Role of Institutional Trust
}

\author{
Marco Ciziceno $^{1} \mathbb{D} \cdot$ Giovanni A. Travaglino ${ }^{2,3}$ (D)
}

Accepted: 26 January 2018 / Published online: 2 February 2018

(C) Springer Science+Business Media B.V., part of Springer Nature 2018

\begin{abstract}
Corruption degrades the quality of institutions, increases economic inequality and limits growth. Recent studies indicate that corruption is also associated with lower satisfaction with life. This research examines a potential explanation for this association and investigates the role of institutional trust in mediating the linkage between perceived corruption and satisfaction with life. Specifically, in two studies, we tested the novel hypothesises that perceived corruption affects life satisfaction indirectly by undermining individuals' confidence in institutions. Study $1(\mathrm{~N}=251)$ involved an opportunity sample from the US. Study $2(\mathrm{~N}=9508)$ analysed data from the World Value Survey and involved a larger, representative sample of individuals from the MENA region. Across studies, mediation analyses provided evidence for the hypothesized indirect effect of perceived corruption on life satisfaction through institutional trust. Implications of the findings, limitations of the studies and directions for future research are discussed.
\end{abstract}

Keywords Corruption $\cdot$ Trust $\cdot$ Life satisfaction $\cdot$ Well-being

Marco Ciziceno and Giovanni A. Travaglino have contributed equally to this work.

Marco Ciziceno

marco.ciziceno@unipa.it

Giovanni A. Travaglino

G.A.Travaglino@kent.ac.uk

1 Department of Economic Sciences, University of Palermo, Palermo, Italy

2 Centre for the Study of Group Processes, School of Psychology, University of Kent, Canterbury, UK

3 School of Humanities and Social Science, The Chinese University of Hong Kong, Shenzhen, China 


\section{Introduction}

Corruption is a barrier to human development that degrades the quality of institutions and increases economic inequality (Tan et al. 2016; Zheng et al. 2016). It distorts public decision making, penalizes innovation, and discourages investments (Akçay 2006; Kaufmann and Wei 1999; Murphy et al. 1993). Recent research indicates that corruption's negative effects extend also to individuals. High levels of perceived corruption are associated with lower levels of subjective well-being and life satisfaction (Bjørnskov et al. 2008; Helliwell 2006; Rothstein 2010).

However, the matter of how corruption affects life satisfaction has not received much attention in the scientific literature (for an exception see Wu and Zhu 2016). A key empirical question is, therefore, which mechanisms explain this association. Identifying these mechanisms may enable practitioners and policy makers to design more effective, evidence-based interventions aimed at improving people's life satisfaction.

In this research, we examine one such a mechanism and propose that corruption reduces individuals' life satisfaction by undermining the trust that individuals have in institutions. Institutional trust refers to the degree of confidence that individuals have in judicial, economic and governmental bodies (Hudson 2006). Institutional trust is essential for the correct functioning of modern democracies, because stronger trust is associated with better civic participation, a sense of reciprocity, endorsement of shared rules and a more predictable environment (Bjørnskov 2003; Pretty and Ward 2001).

Corruption corrodes individuals' trust in institutions because it implies that economic, governmental and judicial bodies are unable to manage public goods and apply procedures fairly (Chang and Chu 2006). Thus, we propose that the negative association between perceived corruption and life satisfaction is at least partly explained by reduced institutional trust. Specifically, we hypothesize the existence of an indirect effect of corruption on life satisfaction via institutional trust. In this research, we test this hypothesis using two studies involving different geographical, socio-political and economic contexts. In study 1 , we investigate the indirect effect of corruption on people's life satisfaction in a sample of 251 North American people. In study 2, we use the same empirical strategy in a larger and representative sample of 9508 individuals from countries belonging to the Middle East and North Africa (MENA) region.

\section{Literature Review and Research Hypotheses}

\subsection{Corruption, Subjective Well-Being and Satisfaction with Life}

Corruption is the misuse of public power in order to obtain private gains (Akçay 2006; Ko and Weng 2011). Corruption strongly affects people's material environment, increasing inequality (Uslaner 2008) and crime (Montinola and Jackman 2002), and lowering the quality of public decisions (Akçay 2006). Because corruption distorts the allocation of resources, it also hampers government performance, undermining economic growth and decreasing the efficiency of public and private institutions (Voliotis 2011). Despite the argument that in some contexts (e.g., underdeveloped countries) corruption may have some positive effects because it eases bureaucratic procedures and encourages extra-legal investments (Leff 1964), overall authors seem to agree on the fact that 
corruption slows economic growth and impairs the government's effectiveness (Montes and Paschoal 2016).

Notably, the consequences of corruption are not only limited to the spheres of economy and governance. Individuals tend to be acutely aware of the presence of corruption in their environment and perceive accurately how corrupted their country is (Lancaster and Montinola 2001; Ko and Samajdar 2010; Mishler and Rose 2001; Wallace and Latcheva 2006). For instance, Pellegata and Memoli (2016) compared citizens' perceived corruption to experts' opinions concerning the levels of corruption across different EU member states. They found that, overall, citizens' estimates matched those of experts.

Thus, research has examined the implications of corruption at the individual level of analysis, in addition to the structural one (Tavits 2008; Uslaner 2003; Seligson 2002). In particular, this research has focused on individuals' life satisfaction. Life satisfaction is the cognitive component of the more general concept of subjective well-being (see Diener et al. 1985). It refers to individuals' evaluation of their own life as a whole and it is generally based on personal judgments about the fulfillment of one's own goals and aspirations (Diener et al. 1985, 2003; Pavot and Diener 2008).

This research indicates that there is a negative association between the subjective experience of corruption and individuals' levels of life satisfaction (Helliwell 2006; Rothstein 2010; Wu and Zhu 2016; Zheng et al. 2016). For instance, using cross-national data from 68 different countries, Tavits (2008) demonstrated that individuals tend to report higher levels of happiness when - among other factors - the government performs well (i.e., the levels of corruption are lower). More recently, Wu and Zhu (2016) used data from the Asian Barometer Survey to demonstrate that perceived corruption impacts negatively on people's life satisfaction in China, especially when the external environment is overall low in corruption. Although these results provide evidence that corruption affects people's life satisfaction, the explanatory process underlying this relationship remains unclear.

\subsection{Institutional Trust as a Mediator}

In general terms, trust is based on the expectation that others behave predictably and honestly (Kubbe 2013: 121; Putnam 1993). At the institutional level, such expectations are about the institutions' social and economic performance (Frey and Stutzer 2002; Kotzian 2011). Thus, institutional trust is formally defined as the degree of confidence that people have in the judicial, economic and governmental bodies (Hudson 2006; Putnam 1993), as well as citizens' evaluations of the performance of such institutions. High levels of institutional trust enable citizens to live in a predictable, stable and controllable environment and, at the same time, contribute to maintain social cohesion because they elicit cooperative behaviors among citizens (Abrams and Travaglino 2018; Levi and Stoker 2000).

Research indicates that perceived corruption reduces social trust in general (Morris and Klesner 2010), and confidence in institutions in particular (Kostadinova 2009; Clausen et al. 2011). This is because high levels of corruption imply that institutions tend to represent particular interests rather than general ones (Kotzian 2011). Thus, when individuals perceive institutions as corrupted, such institutions lose credibility in the eyes of the people and are seen as inefficient (Pellegata and Memoli 2016; see also Seligson 2002; Rothstein and Stolle 2008).

Recently, Clausen et al. (2011) examined the issue of the causal directionality of the relationship between perceived corruption and institutional trust. The authors analyzed data from a Gallup World Poll involving over 150 countries. They used an experiential 
item more likely to be endogenous to participants' perceived levels of trust, as well as bound analyses and provided convincing conceptual and methodological evidence that such a relationship was more likely to flow from corruption to institutional trust, rather than vice versa.

Importantly, there is also substantial evidence that institutional trust is an important determinant of people's sense of life satisfaction and well-being (Hudson 2006; Rose-Ackerman 1999). For instance, Leung et al. (2011) demonstrated the existence of a strong association between the three components of social capital (Coleman 1988), whose core element is trust (Fukuyama 1995; Putnam 1993), and happiness. In addition, Hudson (2006) investigated the impact of institutional trust on well-being across European countries. He showed that confidence in a range of different institutions, including the National Government, the European Central Bank, the judicial system, the European Union, the UN and big business, had a considerable impact on individuals' life satisfaction. He also demonstrated that, across countries, any adverse experience with such institutions resulted in a generalized loss of trust.

\section{Hypotheses and Analytical Strategy}

In this research, we investigate the relationship between corruption and life satisfaction in two different samples and geographical contexts, the USA (a richer and developed economy) and countries from the MENA region (poorer and developing economies). Furthermore, we test the proposition that institutional trust mediates this relationship. Specifically, we test the contention that one of the ways in which perceived corruption reduces an individual's level of life satisfaction is by undermining her trust in institutions.

On the basis of previous research on corruption and trust (e.g., Clausen et al. 2011; Kostadinova 2009) and trust and well-being (Rose-Ackerman 1999; Hudson 2006), we hypothesize that perceived corruption is associated with a reduced level of institutional trust $(\mathrm{H} 1)$ and that lower institutional trust predicts lower levels of life satisfaction $(\mathrm{H} 2)$. Finally, we hypothesize the existence of an indirect effect of perceived corruption on life satisfaction, through institutional trust (H3).

To test H3, we use a mediation analysis (Hayes 2013) and the SPSS Process Macro ${ }^{1}$ (model 4). Mediation analyses enable researchers to investigate the mechanism through which one variable may affect another through a third explanatory variable. They are useful tools to test hypotheses about whether the effect of a variable X (perceived corruption in the context of this research) is transmitted on variable Y (life satisfaction) through another variable M (institutional trust) (see Fig. 1).

In study 1 , we test our hypotheses in a sample of 251 Americans' citizens, whereas in study 2 we used a larger and representative sample of 9508 individuals from Mena region countries. In both studies, age, sex, education level and annual income of participants were entered as covariates in the model to control for their effects and influence. Equations 1 and 2 express the model for $\mathrm{i}$-th individual:

$$
\text { TRUST }_{\mathrm{i}}=\beta_{0}+\beta_{1} \mathrm{COR}_{\mathrm{i}}+\boldsymbol{\beta}_{2} \text { CONTROL }_{\mathbf{i}}+\varepsilon_{1}
$$

\footnotetext{
1 To run analyses with software other than SPSS (Wilson et al. 2014), data from study 1 are available from the corresponding author upon request, whereas data from study 2 are available online at http://www.world valuessurvey.org/wvs.jsp. Full annotation tables and SPSS scripts are available upon request. For more details about the PROCESS macro see: http://www.processmacro.org/index.html.
} 


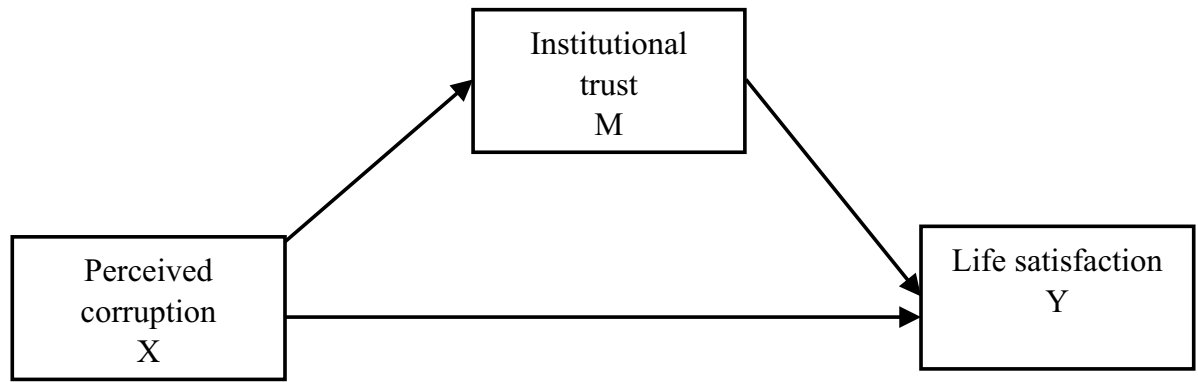

Fig. 1 Mediation model of institutional trust in the relationship between perceived corruption and people's life satisfaction

$$
\text { LIFE }_{i}=\gamma_{0}+\gamma_{1} \text { TRUST }_{i}+\gamma_{2} \text { COR }_{i}+\gamma_{3} \text { CONTROL }_{i}+\varepsilon_{2}
$$

where $\beta_{1}$ is the effect of perceived corruption on institutional trust (the mediator), $\boldsymbol{\beta}_{2}$ is a vector of coefficients for the control variables (i.e., age, sex, education level and annual income) and $\varepsilon_{1}$ is the error (Eq. 1). In the Eq. (2), $\gamma 1$ is the effect of the mediator (institutional trust) on life satisfaction controlled for $\gamma 2$ (i.e., the effect of perceived corruption) and $\gamma_{3}$ (i.e., a vector of coefficients for the control variables included in the model), whilst $\varepsilon_{2}$ is the error. According the product of coefficients approach (MacKinnon et al. 2002), the indirect effect is given by the simple product of $\hat{\beta}_{1} * \hat{\gamma}_{1}$ (standard errors estimated via bootstrap). Note that the circumflex accents above each parameter indicate the estimate of the coefficient in Eqs. (1) and (2).

\section{Study 1: The US Sample}

\subsection{Method}

\subsubsection{Participants and Procedure}

A total of 251 American citizens (107 males and 144 females) participated in the study. Participants were aged between 19 and 74 years old $\left(\mathrm{M}_{\mathrm{age}}=34.21, \mathrm{SD}_{\mathrm{age}}=11.12\right)$. Annual income was measured using four categories, ranging from " $\$ 0.00$ level income" to "\$100.000 and more". Just over a third (34.3\%) of participants reported an annual income of less than, or equal to $\$ 14.999,28.7 \%$ reported an annual income ranging between $\$ 15.000$ and $\$ 39.999,27.6 \%$ had annual income between $\$ 40.000$ and $\$ 79.999$, and only $9.4 \%$ reported an annual income greater than $\$ 79.999$. The ratio of participants with a college-education or a higher education level (i.e., master degree and doctoral degree) was 85.7 and $14.3 \%$ had received only a primary or lower level of education.

Participants were recruited via on-line data collection software, ${ }^{2}$ in April 2016. They were invited to participate in a study "about social issues" and were informed that participation in the study was completely anonymous. Participants received a small monetary

${ }^{2}$ https://www.qualtrics.com/login/. 
incentive at the end of the survey. The overall response rate was approximately $99 \%$. This response rate is based on the number of questionnaires started vs. completed.

\subsubsection{Materials}

4.1.2.1 Perceived Corruption A three-item measure of perceived corruption was used in the study. The items were adapted from previous studies (Tan et al. 2016; Li et al. 2016) and from The Corruption perception index (2015) provided by Transparency International. ${ }^{3}$ All items were measured on a seven-point scale ranging from $1=$ strongly disagree to 7 = strongly agree. Sample items were "In general, corruption is a very common phenomenon in my country and spreads to almost every industry" and "Every civil servant and politician in my country is corrupted". The average score of the items was calculated as a general indicator of perceived corruption. The reliability of the scale reached conventional levels of acceptability $(\alpha=.72)$.

4.1.2.2 Institutional Trust A five-item measure of confidence in institutions was used as a measure of institutional trust. The variable was assessed by asking respondents to express their degree of confidence in Police, Banks, Judicial System, Health Care System and Government. All items were measured on a seven-point scale, ranging from $1=$ no confidence at all to $7=$ a great deal of confidence. The average score was calculated as indicator of institutional trust. To check that all the five trust items loaded on the same factor, we performed a factor analysis by using principal components as method of extraction. The analysis yielded a one-factor solution (range factor loadings .78 to .84) and the scale had a good reliability $(\alpha=.86)$.

4.1.2.3 Life Satisfaction We used the Satisfaction with Life Scale (Diener et al. 1985) in order to assess people's satisfaction with their lives and the achievement of their goals. Sample items were "I am satisfied with my life" and "So far I have gotten the important things I want in life". All items were measured on a seven-point scale, ranging from $1=$ strongly disagree to $7=$ strongly agree. The average score was calculated as indicator of people's life satisfaction. Higher scores indicated greater satisfaction with life. This was a very reliable scale $(\alpha=.93)$.

\subsection{Results and Discussion}

\subsubsection{Preliminary Analyses}

Items' means and standard deviations are reported in Table 1. Correlation coefficients among variables are presented in Table 2 . Perceived corruption was negatively associated with institutional trust (in line with H1) and age. Notably, and seemingly in contrast with previous literature, the correlation between perceived corruption and life satisfaction was not statistically significant. Supporting H2, institutional trust was strongly correlated with life satisfaction and only weakly related to income. Finally, individual's annual income was associated with all other variables but perceived corruption.

3 http://www.transparency.org/cpi2015. 
Table 1 Means and standard deviations for all items used in study 1

\begin{tabular}{lll}
\hline Items & M & SD \\
\hline Corruption perception (average scale score) & 4.42 & 1.088 \\
1. In general, corruption is a very common phenomenon in my country and & 5.12 & 1.314 \\
$\quad$ spreads to almost every industry & & \\
2. Most people who have opportunities to be corrupted, will be corrupted & 4.65 & 1.369 \\
3. Every civil servant and politician in my country is corrupted & 3.51 & 1.638 \\
Institutional trust (average scale score) & 3.78 & 1.355 \\
1. I have confidence in the Police & 4.37 & 1.730 \\
2. I have confidence in the Banks & 3.92 & 1.774 \\
3. I have confidence in the Health Care System & 3.75 & 1.658 \\
4. I have confidence in the Judicial Systems & 3.65 & 1.649 \\
5. I have confidence in the Government & 3.24 & 1.590 \\
Life satisfaction (average scale score) & 4.42 & 1.557 \\
1. In most way my life is close to my ideal & 4.40 & 1.700 \\
2. The conditions of my life are excellent & 4.45 & 1.699 \\
3. I am satisfied with my life & 4.67 & 1.785 \\
4. So far I have gotten the important things I want in life & 4.75 & 1.652 \\
5. If I could live my life over, I would change almost nothing & 3.84 & 1.909 \\
\hline
\end{tabular}

Table 2 Correlation matrix for all variables used in study 1

\begin{tabular}{llllllll}
\hline & 1 & 2 & 3 & 4 & 5 & 6 & 7 \\
\hline Perceived corruption (1) & - & & & & & \\
Institutional trust (2) & $-.284^{* *}$ & - & & & & \\
Life satisfaction (3) & -.010 & $.345^{* *}$ & - & & & \\
Age (4) & $-.185^{* *}$ & .048 & -.095 & - & & \\
Gender (5) & .004 & -.059 & .110 & .187 & - & & \\
Education (6) & -.086 & .099 & .090 & .058 & -.080 & - & \\
Income (7) & -.115 & $.148^{* *}$ & $.212^{* *}$ & $.179^{* *}$ & $-.132^{*}$ & $.360^{* *}$ & - \\
\hline
\end{tabular}

$* p<.05, * * p<.01$

In order to investigate further the relationship between perceived corruption and life satisfaction we ran a regression analysis. Control variables added in the model were, age, sex (coded: $0=$ male, $1=$ female) education level and annual income. All the continuous variables were standardized prior to analyses. Results of these preliminary analyses do not support the existence of a direct link between perceived corruption and life satisfaction. We then proceeded to test the indirect effect of perceived corruption to life satisfaction through institutional trust.

\subsubsection{Mediation Analysis}

The models predicting trust in institutions (the mediator), $F(5,244)=5.40, p<.001$, $R^{2}=.01$, and life satisfaction (the outcome), $F(6,243)=10.88, p<.001, R^{2}=.21$, were both significant. As predicted, and in line with $\mathrm{H} 1$ higher level of perceived corruption 
Table 3 Results of Mediation Analysis: direct and indirect effects of corruption perception (X) on people's life satisfaction (Y) considering institutional trust (M)

\begin{tabular}{lllllll}
\hline & $\mathrm{b}$ & $\mathrm{SE}$ & $\mathrm{t}$ & $p$ & LLCI & ULCI \\
$\begin{array}{l}\text { Model without mediator } \\
\text { Perceived corruption }\end{array}$ & .1364 & .0864 & 1.5786 & .1157 & -.0338 & .3067 \\
$\begin{array}{l}\text { Model with mediator } \\
\text { Perceived corruption }\end{array}$ & $\mathrm{b}$ & Boot SE & $\mathrm{t}$ & $p$ & LLCI & ULCI \\
\hline
\end{tabular}

$* p<.05, * * p<.01$

were significantly associated to lower institutional trust, $b=-.34, S E=.08, p<.001$. In line with $\mathrm{H} 2$, institutional trust (the mediator) positively predicted people's life satisfaction $b=.42, S E=.07, p<.001$. After controlling for demographic variables and for the effect of the mediator, the direct effect of perceived corruption was not significantly associated with people's life satisfaction $b=.14, S E=.09, p=.115$. We then estimated the indirect effect of perceived corruption on life satisfaction through institutional trust using five-thousand bootstraps for the estimates (see Table 3).

In line with $\mathrm{H} 3$, the indirect effect was significant demonstrating that institutional trust mediated the negative effect of perceived corruption on people's life satisfaction $b=-.14$, $S E=.04$. The indirect effect was significant as indicated by the absence of 0 in the $95 \%$ confidence interval $[95 \% \mathrm{CI}=-.25$ to -.07$]$. $^{4}$

Study 1 provided preliminary evidence for the hypothesis that institutional trust explains the relationship between perceived corruption and life satisfaction. Individuals who perceived their country as more corrupt also reported lower trust in their institutions, which in turn lowered their satisfaction with life. However, Study 1 had some limitations. In this study, we tested our hypotheses in a relatively small, ad hoc sample from the richer region of the world. To provide a stronger test of the hypotheses we used data from the World Value Survey and investigated the model in a larger and representative sample of 9508 individuals from a relatively less developed region.

\section{Study 2: The MENA Region Sample}

\subsection{Method}

Study 2 aimed to replicate results from Study 1 in another geographical context and with a larger and representative sample. Data were retrieved from the World Value Survey (WVS) - Wave 6 (2010-2014) which included measures of perceived corruption, institutional trust, and life satisfaction, among others. Perceived corruption items were only available for the following countries from the Middle East and North Africa (MENA) region: Algeria, Bahrain, Iraq, Jordan, Kuwait, Lebanon, Tunisia and Yemen. We therefore focus on this sub-set of countries to test our hypotheses. MENA Countries are relatively poorer economies and therefore provide an interesting setting to investigate the

\footnotetext{
4 As a further check, we also tested the statistical significance of the indirect effect of institutional trust using the Sobel test (1982), obtaining the same results $[b=-.14, S E=.044, z=-3.53, p=.004]$.
} 
Table 4 Descriptive statistics for all countries included in study 2
Country/demographic variables

\begin{tabular}{|c|c|c|c|}
\hline \multicolumn{4}{|l|}{ Algeria } \\
\hline Gender & 1200 & 1.49 & 0.500 \\
\hline Age & 1200 & 37.80 & 15.105 \\
\hline Education & 1199 & 4.60 & 2.737 \\
\hline Annual income & 1200 & 4.68 & 2.015 \\
\hline \multicolumn{4}{|l|}{ Bahrain } \\
\hline Gender & 1200 & 1.45 & 0.498 \\
\hline Age & 1200 & 39.30 & 13.969 \\
\hline Education & 1200 & 5.55 & 2.420 \\
\hline Annual income & 971 & 6.03 & 2.117 \\
\hline \multicolumn{4}{|l|}{ Iraq } \\
\hline Gender & 1200 & 1.48 & 0.500 \\
\hline Age & 1200 & 36.61 & 13.398 \\
\hline Education & 1198 & 4.91 & 2.619 \\
\hline Annual income & 1191 & 5.35 & 1.859 \\
\hline \multicolumn{4}{|l|}{ Jordan } \\
\hline Gender & 1200 & 1.50 & 0.500 \\
\hline Age & 1200 & 39.78 & 15.456 \\
\hline Education & 1200 & 5.21 & 2.496 \\
\hline Annual income & 1195 & 4.99 & 2.072 \\
\hline \multicolumn{4}{|l|}{ Kuwait } \\
\hline Gender & 1258 & 1.36 & 0.481 \\
\hline Age & 1245 & 36.49 & 11.705 \\
\hline Education & 1263 & 6.82 & 1.997 \\
\hline Annual income & 1143 & 5.92 & 2.054 \\
\hline \multicolumn{4}{|l|}{ Lebanon } \\
\hline Gender & 1200 & 1.51 & 0.500 \\
\hline Age & 1200 & 38.37 & 14.854 \\
\hline Education & 1182 & 6.20 & 2.391 \\
\hline Annual income & 1192 & 5.83 & 1.954 \\
\hline \multicolumn{4}{|l|}{ Tunisia } \\
\hline Gender & 1205 & 1.47 & 0.500 \\
\hline Age & 1205 & 38.82 & 16.208 \\
\hline Education & 1204 & 4.12 & 2.705 \\
\hline Annual income & 1154 & 4.68 & 2.066 \\
\hline \multicolumn{4}{|l|}{ Yemen } \\
\hline Gender & 1000 & 1.50 & 0.500 \\
\hline Age & 1000 & 35.59 & 13.278 \\
\hline Education & 998 & 3.48 & 2.844 \\
\hline Annual income & 968 & 3.56 & 2.153 \\
\hline \multicolumn{4}{|l|}{$M E N A$} \\
\hline Gender & 9463 & 1.47 & 0.048 \\
\hline Age & 9450 & 37.84 & 1.491 \\
\hline Education & 9444 & 5.11 & 1.086 \\
\hline Annual income & 9014 & 5.13 & 0.833 \\
\hline
\end{tabular}


relationship between corruption and life satisfaction, and the mediating role of institutional trust in institutions.

\subsubsection{Participants and Procedure}

A total of 9508 people $\left(\mathrm{M}_{\mathrm{age}}=37.89, \mathrm{SD}_{\mathrm{age}}=14.38\right)$ from eight countries belonging to the MENA region were included in the analyses. Table 4 summarizes sample characteristics in each country. Across countries, the sample included 5018 males and 4445 females (45 participants did not report their gender). Education was measured using an ordinal-level scale from $1=$ no formal education to $9=$ university-level education, with degree. About $34.9 \%$ of the sample had completed primary school education or less, $40 \%$ had at least some form of secondary education, and $25.1 \%$ had at least some form of university level education. In the WVS, annual income is measured using a scale with ten steps ranging from 1 (lowest income group) to 10 (highest income group). The average income was $5.15\left(\mathrm{SD}_{\text {income }}=2.17\right)$.

\subsubsection{Materials}

5.1.2.1 Perceived Corruption A two-item scale was used to tap participants' perception of corruption in their country. The two items asked "How widespread do you think that corruption is within businesses in your country?" and "How widespread do you think that corruption is within the government in your country?" (from 1 = none/low corruption to $10=$ high corruption). The two items were strongly correlated $(\mathrm{r}=.82)$ and were therefore averaged in a scale.

5.1.2.2 Institutional Trust In this study, a fourteen-item measure of confidence in institutions was used. The stem of the item was "I am going to name a number of organizations. For each one, could you tell me how much confidence you have in them?" (from $1=$ a great deal to $4=$ none at all). The list of 14 institutions included in this study were drawn from a larger list of 17 institutions. Selection of an institution for inclusion depended on whether it was used in all the countries included in the analysis (to limit number of missing data and preserve sample characteristics). The institutions were: the churches, the press, television, the police, the courts, the government, parliament, the civil service, universities, companies, banks, environmental organisations, women's organisations and charitable or humanitarian organisations. This is a wider range of institutions relative to those used in Study 1. To examine whether all items loaded on the same factor, we performed a factor analysis on the fourteen items using principal components as method of extraction. The analysis yielded a two-factor solution with one major factor explaining $49.17 \%$ of the variance and a lesser factor explaining only $8.69 \%$ of the variance. Items were therefore averaged to form a scale of institutional trust $(\alpha=.92)$. The scale was reversed and in the following analyses higher score indicates stronger trust in institutions.

5.1.2.3 Life Satisfaction The WVS uses one item to measure satisfaction with life, "All things considered, how satisfied are you with your life as a whole these days?", (from $1=$ completely dissatisfied to $10=$ completely satisfied $)$. 
Table 5 Means and standard deviations for all items used in study 2

\begin{tabular}{llr}
\hline Items & $M$ & $S D$ \\
\hline Corruption perception (average scale score) & 6.57 & 2.924 \\
1. How widespread corruption is within businesses in your country? & 6.48 & 3.052 \\
2. How widespread corruption is within the government in your country? & 6.67 & 3.082 \\
Institutional trust (average scale score) & 2.46 & .671 \\
1. I have confidence in the Churches & 2.02 & .984 \\
2. I have confidence in the Press & 2.80 & .921 \\
3. I have confidence in Television & 2.65 & .934 \\
4. I have confidence in the Police & 2.25 & 1.000 \\
5. I have confidence in the Courts & 2.32 & 1.017 \\
6. I have confidence in the Government & 2.62 & 1.049 \\
7. I have confidence in the Parliament & 2.95 & 1.001 \\
8. I have confidence in the Civil service & 2.69 & .972 \\
9. I have confidence in the Universities & 2.37 & .958 \\
10. I have confidence in the Major companies & 2.61 & .962 \\
11. I have confidence in the Banks & 2.48 & .989 \\
12. I have confidence in the Environmental organizations & 2.59 & .974 \\
13. I have confidence in the Women's organizations & 2.71 & .970 \\
14. I have confidence in the Charitable or humanitarian organizations & 2.44 & .987 \\
Life satisfaction & & \\
1. I am satisfied with my life & 6.36 & 2.329 \\
\hline
\end{tabular}

Table 6 Correlation matrix for all variables used in study 2

\begin{tabular}{llllllll}
\hline & 1 & 2 & 3 & 4 & 5 & 6 & 7 \\
\hline Perceived corruption (1) & - & & & & & \\
Institutional trust (2) & $-.227^{* *}$ & - & & & & \\
Life satisfaction (3) & $-.032^{*}$ & $.151^{* *}$ & - & & & & \\
Age (4) & .003 & $.063^{* *}$ & $-.051^{* *}$ & - & & & \\
Gender (5) & -.007 & $.037^{* *}$ & $0.21^{*}$ & .008 & - & & \\
Education (6) & -.010 & $.043^{* *}$ & $.168^{* *}$ & $-.281^{* *}$ & $-.102^{* *}$ & - & \\
Income (7) & $-.054^{* *}$ & $.147^{* *}$ & $.294^{* *}$ & $-.087^{* *}$ & -.010 & $.313^{* *}$ & - \\
\hline
\end{tabular}

$* p<.05, * * p<.01$

\subsection{Results and Discussion}

\subsubsection{Preliminary Analyses}

Items' means and standard deviations are reported in Table 5. Intercorrelations among variables are summarised in Table 6. Interestingly, and in line with previous literature (Tavits 2008; Helliwell 2008; Welsch 2008), in this study the direct link between perceived corruption and life satisfaction was significant albeit small $(r=-.03, p=.002)$. Perceived corruption was associated negatively with life satisfaction, demonstrating that people who 
Table 7 Results of Mediation Analysis: direct and indirect effects of corruption perception (X) on people's life satisfaction (Y) considering institutional trust (M) in study 2

\begin{tabular}{lllllll}
\hline & $\mathrm{b}$ & $\mathrm{SE}$ & $\mathrm{t}$ & $\mathrm{p}$ & $\mathrm{LLCI}$ & ULCI \\
$\begin{array}{l}\text { Model without mediator } \\
\text { Perceived corruption }\end{array}$ & 0.119 & .0084 & 1.4175 & .1564 & -.0046 & .0285 \\
$\begin{array}{l}\text { Model with mediator } \\
\text { Perceived corruption }\end{array}$ & $\mathrm{b}$ & Boot SE & $\mathrm{t}$ & $\mathrm{p}$ & LLCI & ULCI \\
& -.0215 & .0023 & - & - & -.0261 & -.0171 \\
\hline
\end{tabular}

$* p<.05, * * p<.01$

perceived their environment as more corrupt were also more likely to be less satisfied with life. Table 6 shows that there were small, but systematic associations between the covariates, perceived corruption, institutional trust and life satisfaction. Therefore, and in line with Study 1, in the subsequent analyses we control for the influence of age, gender, income and education levels on both the mediator and the outcome.

\subsubsection{Mediation Analysis}

To test the hypothesis that institutional trust mediates the relationship between perceived corruption and life satisfaction, and in line with Study 1, we ran a mediation analysis using Hayes' (2013) Process macro (model 4). Differences in the degrees of freedom in the models below are due to missing observations in the dataset.

The models predicting trust in institutions (the mediator), $F(5,8783)=146.12$, $p<.001, R^{2}=.08$, and life satisfaction (the outcome), $F(6,8782)=172.41, p<.001$, $R^{2}=.11$, were both significant. In line with $\mathrm{H} 1$, higher levels of perceived corruption were systematically associated with lower levels of institutional trust, $b=-.05 S E=.01$, $p<.001$. In line with $\mathrm{H} 2$, institutional trust (the mediator) positively predicted people's life satisfaction, $b=.42 S E=.04, p<.001$. People who had more confidence in their institutions, also reported more satisfaction with life. Controlling for the demographics and the effect of the mediator, the direct effect of perceived corruption was not significantly related to satisfaction with life, $b=-.012 S E=.01, p=.16$.

Supporting $\mathrm{H} 3$, the indirect effect of perceived corruption on life satisfaction through institutional trust was significant and negative, $b=-.02 \mathrm{SE}=.002,[95 \% \mathrm{CI}=-.03$ to $-.02] .^{5}$

Replicating Study 1 and in line with the hypotheses, we found evidence that institutional trust mediates the relationship between perceived corruption and life satisfaction. Individuals who perceived their environment as more corrupted, also have less confidence in their institutions. This in turn predicted lower satisfaction with life. The effects held also controlling for gender, age and income (see Table 7).

5 The Sobel test provided equivalent results, $b=-.02, S E=.002, z=-10.08, p<.001$. 


\section{General Discussion}

This research investigated the important question of how perceived corruption affects individuals' satisfaction with life. We drew on research on corruption and well-being (Tavits 2008; Hudson 2006; Welsch 2008), and institutional trust (Seligson 2002; Rothstein and Stolle 2008) and proposed that the degree of trust individuals have in their institutions explains (i.e., mediates) the relationship between perceived corruption and satisfaction with life. Specifically, we hypothesized that the more individuals perceive their environment as corrupt, the less they trust institutions. In turn, we hypothesized that lower trust in institutions is associated with lower satisfaction with one's life. Using two studies and two different samples from the USA (a richer context) and the MENA region (a poorer context) we found convincing evidence in support of these hypotheses.

Study 1 involved a convenience sample of 251 people from the USA. In this study, there was no direct association between perceived corruption and life satisfaction. Wu and Zhu (2016) demonstrated that the environment plays an important role in the association between these two variables, in the Chinese context. Future research should investigate the role of the environment in moderating the link between perceived corruption and life satisfaction also in the North American context.

Importantly, in line with our hypotheses, results from Study 1 showed an indirect effect of perceived corruption on life satisfaction through institutional trust. This result is consistent with previous research demonstrating that the credibility of institutions influences people's life satisfaction (Kotzain 2011; Bjørnskov 2006; Helliwell 2006; Hudson 2006). For instance, when citizens have confidence in the judicial system, the Government or the banks they feel their rights are more strongly protected, which is then reflected in stronger satisfaction with life (Frey and Stutzer 2000). Perceived corruption is detrimental to individuals' confidence in institutions because it implies that public goods are not managed fairly (Anderson and Tverdova 2003; Chang and Chu 2006).

Study 2 replicated these findings in a different geographical and socio-economic context. A limitation of Study 1 was that it was based on relatively small sample, which was not representative of the North American population. In study 2 we used data from the WVS and focused on the subset of countries which had data on the constructs needed to test our hypotheses. This enabled us to test our model on a total sample of 9508, representative of 8 countries belonging to MENA region (see Table 4 for full list).

Supporting our hypotheses, and replicating results from Study 1, Study 2 demonstrated that when people perceive corruption to be widespread in their environment they lose confidence in institutions and tend to be more dissatisfied with life (see also Ryan and Deci 2001; Warren 2004). This result supports the generalization of the findings to countries with a different type of governance system and characterized by different types of institutions. This result also contributes to the literature on corruption by examining the relationship between perceived corruption and life satisfaction in poorer, developing economies. Specifically, previous research (e.g., Leff 1964) has argued that in such in economies corruption may have positive implications because it 'greases the wheels' of commerce and makes individuals' relationship with bureaucracies or other services smoother.

However, results from Study 2 also suggest that corruption remains detrimental to individuals' life satisfaction in such contexts because it undermines their trust in institutions. Future research can investigate the differences and similarities between developed and underdeveloped contexts directly, designing studies with comparable measures and samples across the two regions. 


\section{Limitations, Directions for Future Research and Conclusions}

In this paper, we have reported evidence regarding the role played by institutional trust in explaining the relationship between individuals' perceived corruption and life satisfaction. The studies contribute to our understanding of the mechanisms through which perceived corruption is associated to individuals' well-being. Institutions play a key role in maintaining social order and stability within a society. This research demonstrates that, to the extent that perceived corruption undermines confidence in institutions, it indirectly affects individuals' satisfaction with life. A priority for policy-makers should be that of monitoring, sustaining and creating means for boosting individuals' confidence in institutions (Bjørnskov 2006).

This study is affected by some limitations. First, the cross-sectional nature of the data does not enable us to draw strong causal conclusions about the model. It should be noted that previous research has tackled the issue of causal directionality between perceived corruption and institutional trust (Clausen et al. 2011) and between institutional trust and life satisfaction (Hudson 2006). Such research provides importance evidence in support of the causal flow hypothesized in the present article. Moreover, a cross-sectional indirect effect is a necessary step to provide evidence for the existence of mediation. Future research should use longitudinal and experimental studies to test how the relationship between perceived corruption, trust in institutions and life satisfaction changes over the time, as well as testing the causal directionality between variables directly.

Another limitation of this study concerns the sample used in Study 1. Study 1 used an opportunity sample from the US. Results cannot be therefore generalized to the entire population. However, the hypothesized relationship also emerged in countries from MENA region, using a representative sample. Future research should test the relationship between perceived corruption, institutional trust and satisfaction with life in different contexts, and use samples from different populations and geographical areas.

Both the studies presented in this article used an aggregate index of institutional trust which spanned several institutions, across different North American States (Study 1) and MENA Countries (Study 2). An equivalent methodological approach has been used in previous research which has measured institutional or political trust across countries in the world (Anderson and Singer 2008; Clausen et al. 2011; Hakhverdian and Mayne 2012; Klingemann 1999). Similarly, the aggregate measures of corruption used in studies 1 and 2 were either adapted from previous research (Tan et al. 2016; Li et al. 2016) or closely matched those used in previous work (e.g., Clausen et al. 2011).

Importantly, the use of such aggregate measures was in line with the main objective of this article, namely to investigate whether individuals' trust in different institutions mediated the relationship between individuals' perceived corruption and life satisfaction. The advantages of using aggregate indexes is that they provide a more reliable measure of individuals' perception of their environment, because they tap individuals' perception of different contexts and targets. Moreover, results from the reliability and factor analyses indicated that items were highly interrelated with each other, supporting our decision to average across them. Indeed, Hudson (2006: 58-59) found that individuals' adverse social experiences may result in a "generalized loss of trust across all institutions", further supporting the idea that there exists a single underlying factor accounting for individuals' trust in institutions. Nonetheless, future research may use this work as starting point and formulate more specific hypotheses concerning the working and functions of specific institutions, as well as devising more specific items to investigate how different components of 
institutional trust affect individuals' life satisfaction, or are affected by perceived corruption. Future research may also explore how different constructs and variables may explain the association between corruption and life satisfaction, as well as testing their relative contribution.

Results from the present research are in line with the idea that corruption does not only affect individuals' material and economic conditions, but it also affect individuals' psychological sphere (i.e., life satisfaction) by undermining their confidence in institutions. Thus, this research contributes to our understanding of how institutional-level factors (as opposed to individuals' traits) may potentially determine peoples' well-being. More research is needed on this topic.

\section{References}

Abrams, D., \& Travaglino, G. A. (2018). Immigration, political trust, and Brexit-Testing an aversion amplification hypothesis. British Journal of Social Psychology. https://doi.org/10.1111/bjso.12233.

Akçay, S. (2006). Corruption and human development. Cato Journal, 26(1), 29-48.

Anderson, C. J., \& Singer, M. M. (2008). The sensitive left and the impervious right: multilevel models and the politics of inequality, ideology, and legitimacy in Europe. Comparative Political Studies, 41(4-5), 564-599.

Anderson, C. J., \& Tverdova, Y. V. (2003). Corruption, political allegiances, and attitudes toward government in contemporary democracies. American Journal of Political Science, 47(1), 91-109.

Bjørnskov, C. (2003). The happy few: cross-country evidence on social capital and life satisfaction. Kyklos, $56(1), 3-16$.

Bjørnskov, C. (2006). The multiple facets of social capital. European Journal of Political Economy, 22(1), $22-40$.

Bjørnskov, C., Dreher, A., \& Fischer, J. A. (2008). Cross-country determinants of life satisfaction: exploring different determinants across groups in society. Social Choice and Welfare, 30(1), 119-173.

Chang, E. C., \& Chu, Y. H. (2006). Corruption and trust: exceptionalism in Asian democracies? The Journal of Politics, 68(2), 259-271.

Clausen, B., Kraay, A., \& Nyiri, Z. (2011). Corruption and confidence in public institutions: Evidence from a global survey. The World Bank Economic Review, 25(2), 212-249.

Coleman, J. S. (1988). Social capital in the creation of human capital. American Journal of Sociology, 94, S95-S120.

Diener, E. D., Emmons, R. A., Larsen, R. J., \& Griffin, S. (1985). The satisfaction with life scale. Journal of Personality Assessment, 49(1), 71-75.

Diener, E., Oishi, S., \& Lucas, R. E. (2003). Personality, culture, and subjective well-being: Emotional and cognitive evaluations of life. Annual Review of Psychology, 54(1), 403-425.

Frey, B. S., \& Stutzer, A. (2000). Happiness, economy and institutions. The Economic Journal, 110(466), 918-938.

Frey, B. S., \& Stutzer, A. (2002). What can economists learn from happiness research? Journal of Economic Literature, 40(2), 402-435.

Fukuyama, F. (1995). Social capital and the global economy. Foreign Affairs, 74(5), 89-103.

Hakhverdian, A., \& Mayne, Q. (2012). Institutional trust, education, and corruption: A micro-macro interactive approach. The Journal of Politics, 74(3), 739-750.

Hayes, A. F. (2013). Introduction to mediation, moderation, and conditional process analysis: A regressionbased approach. New York: Guilford Press.

Helliwell, J. F. (2006). Well-being, social capital, and public sector: What's new? Economic Journal, 116(510), C34-C45.

Helliwell, J. F. (2008). Life satisfaction and quality of development. NBER working papers, No. w14507. National Bureau of Economic Research. Retrieved http://www.nber.org/papers/w14507.

Hudson, J. (2006). Institutional trust and subjective well-being across the EU. Kyklos, 59(1), 43-62.

Kaufmann, D., \& Wei, S. J. (1999). Does "grease money" speed up the wheels of commerce? NBER working papers, No. w7093. National Bureau of Economic Research. Retrieved http://www.nber.org/paper s/w7093.pdf. 
Klingemann, H. D. (1999). Mapping political support in the 1990s: A global analysis. In P. Norris (Ed.), Critical citizens: global support for democratic government (pp. 31-56). Oxford: Oxford University Press.

Ko, K., \& Samajdar, A. (2010). Evaluation of international corruption indexes: Should we believe them or not? The Social Science Journal, 47(3), 508-540.

Ko, K., \& Weng, C. (2011). Critical review of conceptual definitions of Chinese corruption: A formallegal perspective. Journal of Contemporary China, 20(70), 359-378.

Kostadinova, T. (2009). Abstain or rebel: Corruption perceptions and voting in East European elections. Politics \& Policy, 37(4), 691-714.

Kotzian, P. (2011). Public support for liberal democracy. International Political Science Review, 32(1), 23-41.

Kubbe, I. (2013). Corruption and trust: A model design. Zeitschrift für Vergleichende Politikwissenschaft, 7(1), 117-135.

Lancaster, T. D., \& Montinola, G. R. (2001). Comparative political corruption: Issues of operationalization and measurement. Studies in Comparative International Development, 36(3), 3-28.

Leff, N. H. (1964). Economic development through bureaucratic corruption. American Behavioral Scientist, 8(3), 8-14.

Leung, A., Kier, C., Fung, T., Fung, L., \& Sproule, R. (2011). Searching for happiness: The importance of social capital. Journal of Happiness Studies, 12(3), 443-462.

Levi, M., \& Stoker, L. (2000). Political trust and trustworthiness. Annual Review of Political Science, $3(1), 475-507$.

Li, H., Gong, T., \& Xiao, H. (2016). The perception of anti-corruption efficacy in China: An empirical analysis. Social Indicator Research, 125(3), 885-903. https://doi.org/10.1007/s11205-015-0859-z.

MacKinnon, D. P., Lockwood, C. M., Hoffman, J. M., West, S. G., \& Sheets, V. (2002). A comparison of methods to test mediation and other intervening variable effects. Psychological Methods, 7(1), 83-104.

Mishler, W., \& Rose, R. (2001). What are the origins of political trust? Testing institutional and cultural theories in post-communist societies. Comparative Political Studies, 34(1), 30-62.

Montes, G. C., \& Paschoal, P. C. (2016). Corruption: what are the effects on government effectiveness? Empirical evidence considering developed and developing countries. Applied Economics Letters, 23(2), 146-150.

Montinola, G. R., \& Jackman, R. W. (2002). Sources of corruption: a cross-country study. British Journal of Political Science, 32(01), 147-170.

Morris, S. D., \& Klesner, J. L. (2010). Corruption and trust: Theoretical considerations and evidence from Mexico. Comparative Political Studies, 43(10), 1258-1285.

Murphy, K. M., Shleifer, A., \& Vishny, R. W. (1993). Why is rent-seeking so costly to growth? The American Economic Review, 83(2), 409-414.

Pavot, W., \& Diener, E. (2008). The satisfaction with life scale and the emerging construct of life satisfaction. The Journal of Positive Psychology, 3(2), 137-152.

Pellegata, A., \& Memoli, V. (2016). Can corruption erode confidence in political institutions among European countries? Comparing the effects of different measures of perceived corruption. Social Indicators Research, 128(1), 391-412.

Pretty, J., \& Ward, H. (2001). Social capital and the environment. World Development, 29(2), 209-227.

Putnam, R. D. (1993). Making democracy work, with Robert Leonardi and Raffaella Y. Nanetti. Princeton, NJ: Princeton University Press.

Rose-Ackerman, S. (1999). Corruption and government: causes, consequences, and reform. Cambridge: Cambridge University Press.

Rothstein, B. (2010). Happiness and the welfare state. Social Research: An International Quarterly, $77(2), 441-468$.

Rothstein, B., \& Stolle, D. (2008). The state and social capital: An institutional theory of generalized trust. Comparative Politics, 40(4), 441-459. Retrieved http://www.jstor.org/stable/20434095.

Ryan, R. M., \& Deci, E. L. (2001). On happiness and human potentials: A review of research on hedonic and eudaimonic well-being. Annual Review of Psychology, 52(1), 141-166.

Seligson, M. A. (2002). The impact of corruption on regime legitimacy: A comparative study of four Latin American countries. The Journal of Politics, 64(2), 408-433.

Sobel, M. E. (1982). Asymptotic confidence intervals for indirect effects in structural equation models. In S. Leinhart (Ed.), Sociological methodology (pp. 290-312). San Francisco: Jossey-Bass.

Tan, X., Liu, L., Huang, Z., Zhao, X., \& Zheng, W. (2016). The dampening effect of social dominance orientation on awareness of corruption: Moral outrage as a mediator. Social Indicators Research, $125(1), 89-102$. 
Tavits, M. (2008). Representation, corruption, and subjective well-being. Comparative Political Studies, 41(12), 1607-1630.

Uslaner, E. M. (2003). Trust and civic engagement in East and West. In G. Badescu \& E. Uslaner (Eds.), Social capital and the transition to democracy (pp. 81-94). London: Routledge.

Uslaner, E. M. (2008). Corruption, inequality, and the rule of law: the bulging pocket makes the easy life. Cambridge: Cambridge University Press.

Voliotis, S. (2011). Abuse of ministerial authority, systemic perjury, and obstruction of justice: corruption in the shadows of organizational practice. Journal of Business Ethics, 102(4), 537-562.

Wallace, C., \& Latcheva, R. (2006). Economic transformation outside the law: corruption, trust in public institutions and the informal economy in transition countries of Central and Eastern Europe. EuropeAsia Studies, 58(1), 81-102.

Warren, M. (2004). What does corruption mean in a democracy? American Journal of Political Science, $48(2), 328-343$.

Welsch, H. (2008). The welfare costs of corruption. Applied Economics, 40(14), 1839-1849.

Wilson, G., Aruliah, D. A., Brown, C. T., Chue Hong, N. P., Davis, M., Guy, R. T., et al. (2014). Best practices for scientific computing. PLoS Biology, 12(1), e1001745. https://doi.org/10.1371/journ al.pbio. 1001745 .

Wu, Y., \& Zhu, J. (2016). When are people unhappy? Corruption experience, environment, and life satisfaction in Mainland China. Journal of Happiness Studies, 17(3), 1125-1147.

Zheng, W. W., Liu, L., Huang, Z. W., \& Tan, X. Y. (2016). Life Satisfaction as a buffer of the relationship between corruption perception and political participation. Social Indicators Research. https://doi. org/10.1007/s11205-016-1318-1. 